\title{
The information needs of patients treated with primary angioplasty for heart attack: An exploratory study
}

\author{
Felicity Astin ${ }^{\mathrm{a}, \mathrm{b}, *}$, S. José Closs ${ }^{\mathrm{b}}$, Jim McLenachan ${ }^{\mathrm{c}}$, Stacey Hunter ${ }^{\mathrm{c}}$, Claire Priestley $^{\mathrm{c}}$ \\ a School of Healthcare, Baines Wing, The University of Leeds, Leeds LS2 9JT, UK \\ ${ }^{\mathrm{b}}$ The University of Leeds, Leeds, UK \\ ${ }^{\mathrm{c}}$ Leeds Teaching NHS Trust, Leeds, UK
}

\section{A R T I C L E I N F O}

\section{Article history:}

Received 8 December 2007

Received in revised form 17 June 2008

Accepted 20 June 2008

\section{Keywords:}

Coronary angioplasty

Primary angioplasty

Myocardial infarction

Health information

Interview study

Coronary heart disease

Patient education

\begin{abstract}
A B S T R A C T
Objective: As early recovery is a challenging period for cardiac patients who frequently have 'unmet' health information needs, the objective of this study was to explore the information needs of patients treated with primary angioplasty for heart attack.

Methods: Qualitative methodology using semi-structured interviews with 29 patients recruited from a specialist English Cardiology centre, 3-12 days after discharge from hospital. Framework analysis techniques were used to synthesise findings.

Results: Participants were generally satisfied with the way in which health information was provided. The need for more specific information about the risk of recurrence, the level of heart muscle damage, discharge medications, appropriate levels of physical activity and diet was highlighted. There was no clear preference for informant and preferences for the timing of information delivery varied considerably. Conclusion: Health information provision was satisfactory for most but could be improved by the closer matching of patients' preferences with provision. The shortened hospital stay, rapid throughput and emotional shock experienced by patients influenced their ability to absorb information making the optimum timing for health information delivery variable.

Practice implications: Current guidelines about the provision of health information for patients recovering from heart attack may need to be reviewed to reflect the recent technological advances in treatment. One approach may be to better 'stage' information to reflect patients' priorities. Home visits by specialist nurses may need to be scheduled earlier to improve continuity of care and address information 'gaps'. Crown Copyright (c) 2008 Published by Elsevier Ireland Ltd. All rights reserved.
\end{abstract}

\section{Introduction}

Cardiovascular disease is the main cause of death in developed countries and will remain so despite a gradual decline in disease rates [1]. Heart attack or myocardial infarction (MI) is one manifestation of cardiovascular disease caused by the blockage of a coronary artery. Primary percutaneous coronary intervention (p-PCI), or primary angioplasty as it is better known, is recommended as the first-line therapy for patients with ST elevation MI [2]. The aim of this treatment is to restore blood flow by physically opening the affected coronary artery. This is achieved under local anaesthetic by the peripheral insertion of a

\footnotetext{
Disclaimer: I confirm that all of the personal identifiers have been removed or disguised so that the persons described are not identifiable and cannot be identified through the details of their story.

* Corresponding author. Tel.: +44 113 3437558; fax: +44 1133437560 .

E-mail address: f.astin@leeds.ac.uk (F. Astin).
}

catheter guided into the coronary circulation under X-ray fluoroscopy. p-PCI is widely used in parts of Europe and America but is a relatively 'new' treatment in the United Kingdom (UK) having been introduced on a trial basis during 2005 [3].

The length of hospital stay for patients treated with conventional approaches for acute MI has decreased from 7 days in 1989, to 5.5 in 1995 [4]. Treatment with p-PCI offers an even shorter average stay of 3 days which is characterised by multiple transfers across settings. Both the clinical and cost effectiveness of primary angioplasty make it an attractive treatment option [2], but an unintended consequence of the shortened hospital stay is the reduction in opportunities for practitioners to provide patients and their families with health information. In light of these developments current approaches to the provision of health information for MI patients may require review.

A logical first step in achieving this is a comprehensive understanding of patients' health information needs, expressed from their own unique perspective [5]. More specifically practitioners need to understand patients' preferences for health 
information delivery such as what content they value, how they would like this delivered to them (e.g. face-to-face, written, video), by whom and at what point during their recovery. These questions shaped study aim which was to explore the self-reported health information needs of MI patients treated with p-PCI during the first 2 weeks of recovery.

The effective provision of appropriate health information is important for individuals living with chronic conditions such as coronary heart disease (CHD). Increased patient satisfaction [6], reduced levels of psychological distress [7] and enhanced perception of control [8] are all variables associated with effective health information provision. Effective communication is also associated with better patient adherence to prescribed medications [9].

The available literature concerning health information provision indicates that patients' information priorities are not always perceived correctly by health care professionals [10]. Nurses are reported to overestimate the quality and amount of information provided and underestimate patients' needs for information at hospital discharge [11-13]. Moreover information and education priorities between patients and health-care professionals often differ [14-15] and patients sometimes express dissatisfaction with information provision prior to discharge [16].

The majority of studies investigating post-MI patient's health information needs have recruited participants hospitalised for the longer period characteristic of conventional treatment. Therefore, findings may be less relevant to those treated with p-PCI. Such studies show that patients recovering from MI [10,17-23] and elective coronary angioplasty [24] have been reported to have 'unmet' information needs.

Much of the published literature originates from America and has relied heavily on quantitative approaches. A systematic review reported that post-MI patients reported coronary risk factors, followed by information about cardiac pathophysiology, medications and physical activity as important topic areas [10]. Some doubt was cast on the reliability and validity of these findings as differences in information needs were evident across studies according to the measurement instrument used, indicating a priming effect [10]. Other topics identified as important by patient's post-MI included information about future treatment choices, prognosis, how their family could support lifestyle changes, the role of each doctor in their treatment and cardiac rehabilitation [25]. A more recent review identified that the information topics most important to post-MI patients were those issues pertinent to their survival at the time, such as symptom management [26]. Findings are inconsistent and may reflect limitations associated with measurement instruments particularly as these are often developed without patient involvement meaning that they may reflect practitioners' priorities rather than patients.

Qualitative studies have found that patients often find it difficult to identify what health information is relevant and useful to them post-MI [20]. Early days after hospital discharge were reported as being the worst period for patients and a time when they were most in need of help and support [29-30]. Patients often reported feeling uncertain, anxious and depressed [20,27]. Preferred health information topics were similar to those reported in quantitative studies [20-21].

Although there has been considerable focus upon the content of health information provision, there is less available information about cardiac patients' preferences for how they would like this delivered to them (e.g. face-to-face, written, video), by whom and at what point during their recovery. Available studies recognise that learning needs vary according to stage of recovery [28-30] and that patients recovering from MI perceived the optimum time for realistic learning to be during early convalescence [31].
Studies examining patients' preferences for informant vary in their findings. Some report that physicians were preferred over nurses as information givers $[10,25]$ whilst others state that cardiac rehabilitation staff are preferred [32]. One explanation for discrepancies across studies is that cardiac patients are not always aware of which health professional might be best placed to provide health information [33]. The provision of written information and verbal information combined, compared to verbal information alone, supports the provision of standardised care information to patients and their families and also appears to improve levels of knowledge and satisfaction [34]. Other media forms such as radio, television, audiotapes and the Internet are less popular with cardiac patients [35]. The expressed needs of patients and their families should be a first step in the process of information provision [5].

\section{Methods}

This qualitative study was the main part of a larger mixed methods study which aimed to explore the information needs of patients treated with primary angioplasty for heart attack. A qualitative approach was chosen as the information needs of this 'new' and expanding group have been largely unexplored. Qualitative methods enabled us to explore the complexity of patients' perspectives and inter-relationships between these [36]. To encourage participants to freely discuss their preferences we chose to conduct one-to-one interviews in a naturalistic setting.

\subsection{Recruitment and data collection}

The study was conducted in a large specialist UK centre which provides p-PCI for a population of 3.1 million. All patients admitted for p-PCI with fluency in spoken English were invited to participate by a research nurse not involved in interviewing. We used purposive sampling to ensure that we included the views of both male and females from younger and older age groups [37]. Seven potential participants refused to take part. Those with prior cardiac history were excluded.

The study was approved by the local research ethics committee. Eligible participants were approached before they were discharged home and written and verbal consent obtained from those who were willing.

All participants were interviewed once, face-to-face, within 312 days of hospital discharge. Interviews took place before a scheduled community cardiac rehabilitation nurse visit. All participants chose to be interviewed at home. Interviews lasted between 40 and $90 \mathrm{~min}$ and were conducted by an experienced interviewer (FA). The timing for interviews was chosen because the literature indicates that the period immediately after discharge from hospital is particularly challenging for patients recovering from MI [27]. Details of a free counselling help line for people with heart disease were included in the participant information sheet in the event that participants became distressed.

A topic guide was used and questions focused upon participants' views about health information provision. In particular participants were asked questions about how they would like health information delivered, the content and informant they preferred as well as the optimum time for health information delivery. Explanatory and clarificatory probes were used to explore the rationales underpinning participants' choices. When no new material was forthcoming to inform the development of new categories and themes data collection was ceased. The final sample comprised 29 participants with a mean age of 60 years (range 3683 ), $59 \%$ were men and $14 \%$ lived alone. 


\begin{tabular}{|c|c|c|}
\hline Themes & Categories and sub categories & Representative quotes \\
\hline $\begin{array}{l}\text { The 'How' of } \\
\text { information provision }\end{array}$ & $\begin{array}{ll}\text { Mode: } & \text { Face-to-face } \\
& \text { Written } \\
\text { Characteristics: Honest, } & \text { Consistent } \\
\text { Plain language } \\
\text { Non-judgemental }\end{array}$ & $\begin{array}{l}\text { Definitely face-to-face I think it makes it a bit more personal (M6) } \\
\text { To have the follow-up to read it up when you've been told and you read it, } \\
\text { it makes more sense in the reading (F19) } \\
\text { It's like with the paramedics, when I asked him what were wrong with me, } \\
\text { you know they were a bit cagey to start with. He said well I'll be honest } \\
\text { and I said well I want you to be honest, just tell me (M3) } \\
\text { As Iong as everybody consistent with the information I don't have a } \\
\text { problem. (F20) } \\
\text { Again you hear them saying things um but its all technical terms and you } \\
\text { don't understand it (M13) } \\
\text { She wasn't judgemental um (short pause) she wasn't pushy, she was just } \\
\text { a nice person I think um she must have been good at her job because } \\
\text { she explained things clearly (F10) }\end{array}$ \\
\hline $\begin{array}{l}\text { The 'What' of } \\
\text { information provision }\end{array}$ & $\begin{array}{l}\text { Content: } \text { Living with \& managing recurrence } \\
\text { Negotiating lifestyle changes \& physical limits } \\
\text { Heart Muscle damage and its implications }\end{array}$ & $\begin{array}{l}\text { I've got to know if there is anything strange sort of happens again, you } \\
\text { know any aches and pains, although I was told that you will feel every } \\
\text { ache and pain (M1) } \\
\text { I would like to be convinced long term that um if I take these changes on } \\
\text { board that its going to give me a future, as opposed to you know just a } \\
\text { series of heart attacks (M13) } \\
\text { You worry is your heart going to be alright? and what damage has been } \\
\text { caused to it (F18) }\end{array}$ \\
\hline $\begin{array}{l}\text { The 'Who' of } \\
\text { information provision }\end{array}$ & $\begin{array}{l}\text { Preferred Informant: Nurses } \\
\text { Doctors } \\
\text { No preference }\end{array}$ & $\begin{array}{l}\text { They are there all the time. They see you, they watch, they know, what's } \\
\text { the consultant know? (F9) } \\
\text { The doctor has actually been there and he can, I think it can make a } \\
\text { better impression upon you as regarding the serious, or whatever, what } \\
\text { has actually been done (M4) } \\
\text { Who gives it is immaterial as long as the information is correct (M1) }\end{array}$ \\
\hline $\begin{array}{l}\text { The 'When' } \\
\text { of information } \\
\text { provision }\end{array}$ & $\begin{array}{l}\text { Immediately } \\
\text { At home } \\
\text { Continuous }\end{array}$ & $\begin{array}{l}\text { I think it's nice to know from the start what is happening (M1) } \\
\text { At home, definitely, because when you're in hospital you don't take it all } \\
\text { in do you? (M13) } \\
\text { I wouldn't say that there's a right or there a wrong time you know (F15) }\end{array}$ \\
\hline
\end{tabular}

Fig. 1. Patients' preferences for health information provision.

\subsection{Analysis}

The interviews were audiotaped (with permission), transcribed verbatim and any identifiers removed. We used Framework analysis methods which provided a systematic approach in which data were sifted, sorted and organised into charts according to key issues and themes [38]. As part of this method, a priori issues and available literature are integrated into the data analysis. As a first step transcripts were read repeatedly to identify key themes and categories. Data were then entered into QSR NVIVO and coded according to categories identified both within and between interviews.

Several approaches were implemented to ensure trustworthiness of findings [39]. Interview transcripts were referred to consistently during analysis and characteristic quotes used to support the credibility of findings. Independent analyses were conducted by two researchers (FA \& SJC) during which a preliminary thematic framework was developed from a sample of 10 transcripts, which following consensus, was used to guide analysis of the remainder. Particular attention was given to nonconformist cases during analysis. All participants were sent a copy of anonymised group findings and the majority (71\%) provided written feedback indicating to what extent group findings reflected their own experiences. This approach supported the credibility of our analyses.
Finally, field notes were taken by the interviewer which detailed the context of each interview and the nature of non-verbal cues exhibited by participants. The interviewer also reflected upon her own emotional responses in response to each interview and the challenges associated with taking the role of observer rather than practitioner. Consideration was given to the interviewer's own personal biases, prior knowledge and assumptions and how these might influence data analysis.

\section{Results}

Patients' preferences for health information were characterised by four themes. Each of these will be presented individually with supporting quotations. In addition Fig. 1 provides the reader with additional examples of the process by which themes and categories were derived from data.

\subsection{The 'How' of health information provision}

When participants were asked about their preferences for health information delivery the majority favoured a verbal, faceto-face approach supplemented by written information as a back up. Participants reasoned that a face-to-face approach enabled them to ask questions, was seen as more personal approach and offered an opportunity for some recipients to gauge the truthful- 
ness of the information being provided. Other delivery approaches used by health professionals considered valuable by participants were the use of videos and heart 'models' to support learning.

There were particular characteristics that were important to participants with regard to health information provision. Participants wanted information that was honest, consistent, easy to understand, written in plain language and non-judgemental.

Participants' emotional reactions to a life-threatening event coupled with the speed of service delivery acted as potential barriers to effective information absorption. Participants were emotionally shocked by what had occurred.

'Within $2 \mathrm{~h}$ I was lying in a bed recovering after what they'd done, it was amazing, a bit of a shock (F10).

As a result written materials were seen as particularly valuable by participants as a way of reinforcing verbal information that was provided during hospital admission.

'If you're sort of like told something the day after you've had an operation or something like that by somebody verbally you know anything can happen and you'll have forgotten about that $2 \mathrm{~h}$ later, if you get what I mean, at least when its down in black and white you can read it, you can reread it at your own time and leisure, you can digest it, you can, you know, I prefer stuff done the old fashioned way down in writing' (M58).

Whilst in hospital some participants received a black and white image of their 'before' and 'after' angiogram showing the restored blood flow in their heart muscle. The image made a significant impact and in the context of the emotional shock and disbelief that participants experienced it represented a valuable form of tangible proof

'That photograph were brilliant, as soon as people saw that they could see summit physical can't they, you can talk all day long, don't mean nothing, but show a photograph providing its genuine, not from somebody else. But no, that were good, that helped, that put peoples mind at rest' (M51).

The image was particularly powerful because it was individualised (i.e. showed participant's own heart) making it more meaningful. Participants were influenced by the image in different ways. For some it functioned as a source of reassurance which buoyed self-confidence. For others it was a reminder that they had undergone primary angioplasty for acute MI. One participant attached the image to her cupboard door as a visual reminder not to smoke cigarettes.

Discussions about alternative approaches to information delivery highlighted computer resources as generally unpopular, particularly amongst older patients who described themselves as 'computer illiterate' or 'too long in the tooth' to learn

'Well I can do without all the electronic things I mean we have all these (laughing) but it's the least, the last one I would want really, I mean face-to-face is as good as anything and I will, and then to have the follow-up to read it up when you've been told and you read it, it makes more sense in the reading' (F74).

It was not only age that influenced participants' preferences but also socioeconomic status. Some younger participants were keen to use computer-based resources but did not have computer access. For these participants the barrier to using computer-based resources was access rather than a lack of motivation.

Participants' preferences broadly matched service delivery and most expressed satisfaction about the resources they had received. However the organisation of services across geographical locations meant that there was inequity in the nature of resources that participants received following discharge from hospital. Although all participants received some form of written information the nature of these varied across geographical location. Some received 'before' and 'after' angiogram images and self-help manuals whilst others did not.

\subsection{The 'What' of information provision}

When participants were asked about what content was most important to them three overlapping topic areas emerged. These were 'Living with and managing the risk of recurrence', 'Negotiating lifestyle changes and physical limits' and 'Heart muscle damage and its implications'.

\subsubsection{Living with and managing the risk of recurrence}

The risk of developing a successive MI was a major concern for participants. The self-monitoring and interpretation of physical signs and symptoms that might herald such an event was an important focus during early recovery. Information about how MI onset might be recognised and how likely such a recurrence might be were priority information topics. Some participants recognised that their awareness of physical symptoms was heightened during early recovery but rationalised that this state would decrease over time

'Mm well I feel because it was such a frightening experience for me, I feel that every little twinge that I feel is, am I having a heart attack again? and those are my concerns really you know probably is my brain is playing tricks on me probably it's the way that I'm feeling it's like every little thing, is it a heart attack coming? or is that supposed to be like that? and things like that, but you know that's the only thing that I go through and I'm just like, I mean I think I'm being paranoid really and it's because like I said because I was so frightened and I'm just being paranoid, it all takes time I suppose' (F47).

Participants received information about what action to take if they developed chest symptoms but recall was variable. Some were able to accurately describe the step-by-step action that they would take if they developed chest pain which reflected clinical guidelines. Others were less clear. For example a 59-year old lady was readmitted to hospital within $48 \mathrm{~h}$ of discharge due to 'fluttering' in her chest. She had not used her prescribed nitrate spray because she had been told that it was unlikely that she would need to use it

'I had a bath and tried to go to sleep and I couldn't, all this time I was getting this fluttering and I phoned the emergency call out service and that's another thing, I would have used the glycerine trinitrate spray but, they always prescribe and she said, the sister said, I don't think you'll need that now, I don't know why it goes into your head but it does (short pause) I needn't use it' (F59).

Participants' beliefs and misconceptions provided a potent backdrop within which communicated information was interpreted.

Early recovery was often characterised by feelings of fear and uncertainty. One manifestation of this was participants' avoidance of day-to-day activities that they perceived might 'bring on' a relapse. Participants were often frightened of being left alone at home during the first few days of their recovery. Most participants acknowledged that the risk of recurrence could potentially be reduced by making healthy lifestyle changes although it was unclear how these intentions translated into practice. 


\subsubsection{Negotiating life changes and physical limits}

During early recovery participants were trying to make sense of what was a 'life changing' event. As part of this process they prioritised the health information according to what they perceived as most important, identified health behaviours they intended to change and integrated these into their daily life. Participants often referred to the 'can's and cannot's' which were seen as a new set of 'rules' or boundaries that needed consideration to minimise future coronary risk.

'I am gonna abide by the rules, so really in a way I have got that knowledge that my father didn't abide by the rules, I mean you can go off, I can have a drink still, I can, but I mean, I am definitely going to stop smoking which is the main factor, my father didn't' (F49).

There were differences of opinion about the value of the new 'rules'. Some participants appeared to accept the new 'rules' as a way of reducing future coronary risk, whereas others found the limitations conflicted with the daily activities that they had little choice in performing on a regular basis, e.g. driving to get shopping. The new 'rules' were anxiety provoking for some participants. For example a 66-year old gentleman who had regularly run marathons prior to his illness felt that the information he had received was not sufficiently individualised. For him the focus on what he 'could not do' rather than what he 'could do' was negative. Others explained that although guidelines about daily activities were useful, the only way to learn was through your own day-today experience. These examples illustrate how a range of participants adjusted to the new boundaries imposed upon them by their condition.

The most appropriate level of physical activity was a particular focus for participants of all ages. The way in which participants interpreted and acted upon such information varied. Often participants had been advised to 'take it easy' but felt uncertain about what this meant and wanted additional guidance. Others found advice about physical activity limits incompatible with their feelings of 'wellness' and energy.

'I could literally dig the garden with the energy that I've got' (M67).

The concept of finding out how 'far' they could go, finding out the 'mark', or how far they could 'push' was a recurring idea. Participants reasoned that there was a physical limit which they could go to, which if exceeded, could have detrimental effects.

Family members often played a significant role in enforcing advice about physical activity levels which was not always welcome. Not all participants acted upon information about physical activity levels. A minority of male participants had no fear about 'overstepping' any perceived physical activity 'mark', rather they disregarded advice and exceeded recommendations. They pushed their physical activities levels to somewhat alarming 'superman' limits and then assessed whether they developed any symptoms. This may represent a mechanism by which they were able to reclaim and retain their male role and identity. Females did not describe similar patterns. This shows how gender might influence the interpretation and acceptance of health information.

Some participants mentioned that they wanted additional advice about diet. Although they had received information on this topic, the nature of this did not always match need. In particular family members often wanted a more practical skill-based approach to dietary information. The menu choices available during hospitalisation were somewhat inappropriate in the light of participant's cardiac condition and often conflicted with information they had received giving somewhat mixed messages
Maybe I could have had a little more dietary advice, because I was quite surprised in the hospital that every meal I got a big sachet of salt, which my own GP said you know avoid it at all costs and then I'm in there cos I've had a heart attack and they're giving me these big sachets of salt (laugh) (M46).

This is a clear example of how environment influences interpretation of information.

After p-PCI participants were prescribed a range of medications. The concept of taking lifelong medications was not always popular, particularly with younger participants. For example a 36-year old gentleman questioned the need for life-long lipid lowering medications. He reasoned that once his serum cholesterol was lowered he could stop taking them. The stigma of taking medications as a sign of physical failing was an issue even at an early stage in his recovery. Moreover there were indications that he would cease taking his medications as prescribed. For others with co-existing chronic conditions the addition of other medications to an already complex regime was a source of concern. On two occasions participants reported receiving insufficient information about discharge medications.

\subsubsection{Heart muscle damage and its implications}

The extent of heart muscle damage and the associated consequences of such damage was a source of concern amongst participants. Accordingly participants generally wanted more detailed information about this topic. The way in which the severity and seriousness of the participant's condition was communicated influenced the way in which participants perceived their condition;

'She actually sat down and said you do realise, do you realise what you've been brought in for? And I says yeah I think so and she says well you've had a heart attack and she said it's been a nasty, you know more of, saying it was quite a nasty one and that was important for me. If she'd just said well you've had a mild heart attack or you've had like a warning I'd have probably just been a bit oh thank God for that and probably a bit more (short pause) I don't know if I would have been, but I probably would have been a bit more, oh well yeah, I'll cut down on this, I'll cut down on that, but because of the way she worded it and the way she stated it, she made me sit up and think ooof it's, if you understand what I mean?' (F49).

Making sense of this information was often challenging for participants and was open to individual interpretation and potential misunderstanding. Some participants had misconceptions about the nature of the damage that had occurred e.g. lung damage rather than heart muscle, whereas others could clearly distinguish between angina and MI at an advanced level of understanding. The notion of heart muscle having the capacity to heal and regenerate was a source of hope, comfort and encouragement.

'The most important information was probably regarding the heart, I've found out now, I didn't know it was like the strongest muscle in your body and er that it repairs itself, that's another thing we didn't know did we really, and er that er there's not as much damage as you think to it, cos over the next few months that's going to get better and get repaired, so that puts your mind at ease knowing that it's going to get better and there's not as much damage as you hopefully think.' (F56).

\subsection{The 'Who' of health information provision}

Participants expressed considerable praise for the practitioners responsible for their care including information provision. In 
discussions about their preferred informant responses varied. Some participants expressed no preference and explained that their priority was rather that information was accurate, consistent and understandable; sometimes participants consulted a range of practitioners as a way of assessing information consistency.

Others had a more hierarchical view preferring doctors as primary informants

'Normally you go straight to the top don't you, the doctor, I mean people it all goes on qualifications doesn't it? I mean it's like in the army' (M57).

Some participants reasoned that nurses had less knowledge and 'passed on' information that was given to them rather than functioning as a 'source' of information. Others preferred nurses as primary informants as they spent more face-to-face time with them and were perceived as accessible and easier to relate to

\section{'Nurses talk my kind of language' (F6).}

Several participants identified 'available time' as a factor that influenced their choice of health information provider. Some perceived doctors to have less available time whilst other expressed this opinion about nurses.

\subsection{The 'When' of health information provision}

Participants' preferences for the timing of health information delivery varied considerably. This highlights the importance of evaluating patients 'readiness' as part of individualised information provision. Some wanted health information immediately whereas others explained that they were 'in shock' and could not absorb much information at such an early stage

'As I went through, I mean I weren't taking, I mean it was just like being in another world, it were like watching telly, yer just weren't taking nowt in' (M57).

The latter preferred to be given information towards the end of their 3-day hospital stay or during early recovery at home. Other participants saw the process of health information provision as a 'continuous chain' and not a process dependent on a 'right' or 'wrong' time.

Physical as well as emotional status functioned as a potential barrier to some participant's ability to absorb information

'Not while you're laid up with all the pipes in like I was, I'd have thought it had been better when you could sort of sit up and take notice' (M64).

Participants were usually seen within 3-5 days of hospital discharge by a community cardiac rehabilitation nurse, but in isolated cases this might be considerably longer. The time between hospital discharge and this visit was a time of considerable uncertainty and represented a 'gap' in care.

\section{Discussion and conclusion}

\subsection{Discussion}

Current health policy emphasises the need for practitioners to support patients to manage chronic conditions (including CHD) more effectively [40]; the provision of appropriate health information is an important part of this process. The provision of information for MI patients treated with p-PCI presents several challenges, particularly during hospitalisation and early recovery. From an organisational perspective $\mathrm{p}-\mathrm{PCI}$ is relatively new in the
UK. By necessity events occur rapidly as for optimum clinical outcome treatment must be received as soon as possible after symptom onset. Accordingly the nature and duration of the hospital stay is different than that of conventional treatment because it is characterised by multiple transfers and is of a shorter duration. These characteristics limit opportunities for the provision of health information.

It is known that cardiac patients often have 'unmet' health information needs but little is known about the actual needs of this 'new' p-PCI group explored in this research. As the study design was based on semi-structured interviews with a small sample of participants treated at a single site, data may not reflect the experiences of patients treated at other health care facilities. Nevertheless, these data provide a starting point from which a 'gap' in the literature can be filled. Moreover, our findings are supported by those reported in a similar unpublished study [41] which supports the transferability of our findings.

Participants' preferences for approaches used to deliver health information, generally matched service delivery and the majority were satisfied. The range of health information resources varied between patients and reflected differences across organisations. The written material was considered particularly valuable to support face-to-face provision as emotional shock and the speed of events influenced participants 'readiness' to absorb information. Other studies have identified the need for written material as patients typically forget approximately half of the information provided [42]. Emotional shock may contribute to this as emotional state is known to bias perceptions of events and influence what people remember [43].

The use of patients own 'before' and 'after' angiogram showing the restored blood flow to the heart post $\mathrm{p}-\mathrm{PCI}$ and was a particularly useful educational adjunct. The image provided tangible proof of events and might also support patient-practitioner discussion about heart attack as an acute manifestation of a chronic disease. Others have used patient drawn images of their own heart as a novel aid to identify and manage causes of distress and a-typical symptoms in cardiac patients [44]. Collaborative discussions about acute versus chronic illness models are important as other studies have shown that patients treated with PCI for angina often have misconceptions about being cured by the procedure [45-46]; quantitative pilot data from this study suggests that participants treated with $\mathrm{p}-\mathrm{PCI}$ for MI share similar misconceptions [47].

Participants also appreciated the use of heart 'models' and videos to communication information but few favoured internetbased information delivery. Other studies have reported that advanced age and lower socioeconomic status function as barriers to the use of internet-based information resources [35,48]. Resources for patients with sensory impairment and for those from Non English Speaking backgrounds are currently under development as these were lacking at the time of the study. As access to services is affected by race, sex and socioeconomic status [49] it seems likely that access to information will be similarly influenced.

Participants were generally satisfied with the content of the information provided, although a preference for additional information about the risk of recurrence, heart muscle damage and lifestyle changes (levels of physical activity, dietary change and information about medication) was identified. These findings are similar to those of other studies [10]. The reality in practice is that information must be individualised as different individuals will have different priorities. This emphasises the need for a collaborative approach in which patients' preferences are clearly identified. 
Participants were divided regarding which health professional was their preferred informant. Other studies have shown similarly varied responses [25,32-33]. The fact that cardiac patients are not always aware of who might be best placed to provide them with health information [33] may explain these results. In addition participants' preferences were influenced by their underlying beliefs and expectations of practitioners' roles. These might not always match current practice.

Of all the aspects of patients' preferences for health information explored, the timing of health information delivery represented the most significant challenge purely because of the variation in responses. This finding is supported by others who have reported that patients learning needs vary according to their stage of recovery [31-33] and that the optimum time for realistic learning is during early convalescence [33]. The rapid throughput of patients and emotional shock experienced by them meant that the ability to absorb information during hospitalisation is somewhat limited. It may be preferable that during hospitalisation health information is organised predominantly around key questions often asked by patients during consultations such as 'what has happened?', 'why to me?' and 'what should I do about it?' [50]. Secondary prevention advice may be given at a later stage according to patient preference supported by the community cardiac rehabilitation team.

\subsection{Conclusion}

Health information provision was satisfactory for most but could be improved by the closer matching of patients' preferences with provision. The shortened hospital stay, rapid throughput and emotional shock experienced by patients influenced their ability to absorb information making the optimum timing for health information delivery variable. Ideally health information provision should be individualised to reflect patients' preferences, but within the constraints of a 3 day hospital stay complicated by multiple transfers it is unclear to what extent this is achievable.

\subsection{Practice implications}

Current guidelines about health information provision for MI patients should be reviewed to reflect the technological advances in MI treatment. Health information should be 'staged' to reflect patients' priorities and home visits scheduled within $24 \mathrm{~h}$ of discharge home to address information 'gaps' and enhance continuity of care. The provision of information resources across organisations should be made more consistent and specific resources developed for those from Non English speaking backgrounds or with sensory impairment.

\section{Acknowledgements}

We wish to thank the participants who gave freely of their time and to Sisters Hague \& Somers who recruited study participants and Ms Dudson and Mrs Allcroft who provide administrative support.

\section{References}

[1] Aboderin I, Ben-Shlomo Y, Lynch JW, Kuh D, Yach D. Life course perspectives on coronary heart disease, stroke and diabetes: key implications for policy and research. Geneva: World Health Organisation; 2002.

[2] Hartwell D, Colquitt J, Loveman E, Clegg AJ, Brodin H, Waugh N, Royle P, Davidson P, Vale L, MacKenzie L. Clinical effectiveness and cost-effectiveness of immediate angioplasty for acute myocardial infarction: systematic review and economic evaluation. Health Tech Assess 2005;17:1-118.

[3] Department of Health. 2005. National Infarct Angioplasty Project, http:/ www.dh.gov.uk accessed 23/10/07.
[4] Edwardon SR. The consequences and opportunities of shortened lengths of stay for cardiovascular patients. J Cardiovasc Nurs 1999;1:1-11.

[5] Forster A, Smith J, Young J, Knapp P, House A, Wright J. Information provision for stroke patients and their caregivers. Cochrane Database Syst Rev 2001. Art. No.: CD001919.

[6] Clark PA, Drain M, Gesell SB, Mylod DM, Kaldenberg DO, Hamilton J. Patient perceptions of quality in discharge instruction. Patient Educ Couns 2005;59: $56-68$.

[7] Booth K, Beaver K, Kitchener H, O'Neill JO, Farrell C. Women's experiences of information, psychological distress and worry after treatment for gynaecological cancer. Patient Educ Couns 2005;56:225-32.

[8] Prinjha S, Chapple A, Herxheimer A, McPherson A. Many people with epilepsy want to know more: a qualitative study. Fam Prac 2005;22:435-41.

[9] Osterberg L, Blasche T. Adherence to medication. N Engl J Med 2005;353: 487-97.

[10] Scott JT, Thompson DR. Assessing the information needs of post-myocardial infarction patients: a systematic review. Patient Educ Couns 2003;50:167-77.

[11] Rose JH, Bowman KF, Kresevic D. Nurse versus family caregiver perspectives on hospitalised older patients: an exploratory study of agreement at admission and discharge. Health Commun 2000;12:63-80.

[12] Bowman KF, Rose JH, Kresevic D. Family caregiving of hospitalised patients. Caregiver and nurse perceptions at admission and discharge. J Geront Nurs 1998;24:8-16.

[13] Clemens EL. Multiple perceptions of discharge planning in one urban hospital. Health Soc Work 1995;20:254-61.

[14] Capirci C, Feldman-Stewart D, Mandoliti G, Brundage M, Belluco G, Magnani K. Information priorities of Italian early stage prostate cancer patients and their health-care professional. Patient Educ Couns 2005;56:174-81.

[15] Choi-Kwon S, Lee SK, Park HA, Kwon SU, Ahn JS, Kim JS. What stroke patients want to know and what medical professionals think they should know about stroke: Korean perspectives. Patient Educ Couns 2005;56:85-92.

[16] Burney M, Purden M, McVey L. Patient satisfaction and nurses' perceptions of quality in an inpatient cardiology population. J Care Qual 2002;16:56-67.

[17] Turton J. Importance of information following myocardial infarction: a study of the self perceived information needs of patients and their spouse/partner compared with the perceptions of nursing staff. J Adv Nurs 1998;27:770-8.

[18] Moser DK, Dracup KA, Marsden C. Needs of recovering cardiac patients and their spouses: compared views. Int J Nurs Stud 1993;30:105-14.

[19] Worth A, Tierney AJ, Watson NT. Discharged from hospital: should more responsibility for meeting patients and carers' information needs now be shouldered in the community? Health Soc Care Commun 2000;398-405.

[20] Hanssen TA, Nordrehaug JE, Hanestad BR. A qualitative study of the information needs of acute myocardial infarction patients and their preferences for follow-up contact after discharge. Eur J Cardiovasc Nurs 2005;4:37-44.

[21] Jaarsma T, Kastermans M, Dassen T, Philipsen H. Problems of cardiac patients in early recovery. J Adv Nurs 1995;21:21-7.

[22] Webster RA, Thompson DR, Mayou RA. The experiences and needs of Gujarati Hindu patients and partners in the first month after a myocardial infarction. Eur J Cardiovasc Nurs 2002;1:69-76.

[23] Oterhals K, Hanestad BR, Eide GE, Hanssen TA. The relationship between inhospital information and patients satisfaction after acute myocardial infarction. Eur J Cardiovasc Nurs 2006;5:303-10.

[24] Kattainen E, Merilainen P, Jokela V. CABG and PTCA patients' expectations of informational support in health-related quality of life themes and adequacy of information in 1-year follow up. Eur J Cardiovasc Nurs 2004;3:149-63.

[25] Stewart D, Abbey SE, Shnek ZM, Irvine J, Grace SL. Gender differences in health information needs and decisional preferences in patients recovering from an acute ischaemic event. Psychosom Med 2004;66:42-8.

[26] Timmins F, Kaliszer M. Information needs of myocardial infarction patients. Eur J Cardiovasc Nurs 2003;2:57-65.

[27] Attebring MF, Herlitz J, Ekman I. Intrusion and confusion- the impact of medication and health professionals after acute myocardial infarction. Eur J Cardiovasc Nurs 2005;4:154-9.

[28] Moynihan M. Assessing the educational needs of post-myocardial infarction patients. Nurs Clin N Am 1984;19:441-7.

[29] Karlik BA, Yarcheski A. Learning needs of cardiac patients: a partial replication study. Heart Lung 1987;6:544-50.

[30] Wingate S. Post-MI patients' perceptions of their learning needs. Dimens Crit Care Nurs 1990;9:112-8.

[31] Chan V. Content area for cardiac teaching: patients' perceptions of the importance of teaching content after myocardial infarction. J Adv Nurs 1990;15: 1139-45.

[32] Higgins RO, Murphy BM, Le Grande MR, Parkinson A, Worcester MUC. Goble A Expressed preferences for health education of patients after percutaneous coronary intervention. J Cardiovasc Prev Rehabil 2005;12:572-9.

[33] Wingham J, Dalal HM, Sweeney K, Evans PH. Listening to patients: choice in cardiac rehabilitation. Eur J Cardiovasc Nurs 2006:5:289-94.

[34] Johnson A, Snadford J, Tyndall J. Written and verbal information versus verbal information only for patients being charged from acute hospital settings to home. Cochrane Database Syst Rev 2003. Art. No.: CD003716.

[35] Thomson NR, Micevski V. A descriptive project evaluation to determine Internet access and the feasibility of using the Internet for cardiac education. Heart Lung 2005;34:194-200.

[36] Mays N, Pope C. Assessing quality in qualitative research. Br Med J 2000;320: $50-2$. 
[37] Mays N, Pope C. Qualitative research: rigour and qualitative research. Br Med J 1995;311:109-12.

[38] Richie J, Spencer L. Qualitative data analysis for applied policy research pgs. In: Bryman A, Burgess RG, editors. Analyzing qualitative data. London: Routledge; 1994.

[39] Lincon Y, Guba E. Naturalistic inquiry. London: Sage; 1985.

[40] Department of Health.2006. Supporting people with long term conditions to self care. http://www.dh.gov.uk accessed 22.7.08.

[41] Sampson F, O'Cathain A, Goodacre S. Is primary angioplasty acceptable to patients and their carers? An evaluation of patient satisfaction with emergency treatment for ST-elevated MI. Unpublished abstract presented at Health Services Research Network and National Institute for Health Research Service Delivery and Organisation Programme joint annual conference. June 5, 2008. Manchester, UK.

[42] Ley P. Satisfaction, compliance and communication. Br J Clin Psychol 1982;21: 241-54.

[43] Wissow LS. Emotional states and information states. Patient Edu Couns 2007; 69:1-2.
[44] Logan RL. Patient drawing as aids to the identification and management of causes of distress and atypical symptoms of cardiac patients. N Z Med J 1986 99:368-71.

[45] Astin F, Jones K. Changes in patients' illness representations before and after elective percutaneous transluminal coronary angioplasty. Heart Lung 2006; 35:293-300.

[46] Wenger NK. Improved quality of life after PTCA: generalizability and concerns. Catheter Cardiovasc Diag 1992;27:95-6.

[47] Astin F, Hunter S, Priestly C, McLenachan J, Closs SJ. Primary PCI patients' perspectives of health information provision: preliminary findings. Eur J Cardiovasc Nurs 2007;6(Suppl. 1):S21.

[48] Steinmark AP, Dornelas EA, Fischer EH. Determinants and barriers to participation in an internet based recovery program for cardiac patients. J Clin Psychol Med Set 2006;13:353-7.

[49] Katz JN. Patient preferences and health disparities. J Am Med Assoc 2001;286: 1506-9.

[50] Helman CG. Disease versus illness. Gen Prac J Royal Coll Gen Prac 1981;31: 548-62. 